\title{
Supramolecular structure of the OXPHOS system in highly thermogenic tissue of Arum maculatum
}

Stephanie Sunderhaus ${ }^{1}$, Jennifer Klodmann ${ }^{1}$, Christof Lenz ${ }^{2}$ and Hans-Peter Braun ${ }^{1 *}$

${ }^{1}$ Institute for Plant Genetics, Faculty of Natural Sciences, Leibniz Universität Hannover, Herrenhäuser Str. 2, D-30419 Hannover, Germany

${ }^{2}$ Applied Biosystems, Frankfurter Str. 129 B, D-64293, Darmstadt, Germany

${ }^{*}$ Corresponding author

Hans-Peter Braun

Institute for Plant Genetics

Leibniz Universität Hannover

Herrenhäuser Str. 2

D-30419 Hannover, Germany

Tel: +49 5117622674

Fax: + 495117623608

e-mail: braun@genetik.uni-hannover.de 


\begin{abstract}
The protein complexes of the mitochondrial respiratory chain associate in defined ways forming supramolecular structures called respiratory supercomplexes or respirasomes. In plants, additional oxidoreductases participate in respiratory electron transport, e.g. the socalled "alternative NAD(P)H dehydrogenases" or an extra terminal oxidase called "alternative oxidase" (AOX). These additional enzymes were previously reported not to form part of respiratory supercomplexes. However, formation of respiratory supercomplexes might indirectly affect "alternative respiration" because electrons can be channeled within the supercomplexes which reduces access of the alternative enzymes towards their electron donating substrates. Here we report an investigation on the supramolecular organization of the respiratory chain in thermogenic Arum maculatum appendix mitochondria, which are known to have a highly active AOX for heat production. Investigations based on mild membrane solubilization by digitonin and protein separation by blue native PAGE revealed a very special organization of the respiratory chain in Arum maculatum, which strikingly differs to the one described for the model plant Arabidopsis thaliana: (i) complex I is not present in monomeric form but exclusively forms part of a I+III 2 supercomplex, (ii) the $\mathrm{III}_{2}+\mathrm{IV}$ and $\mathrm{I}+\mathrm{III}_{2}+\mathrm{IV}$ supercomplexes are detectable but of low abundance, (iii) complex II has fewer subunits than in Arabidopsis thaliana, and (iv) complex IV is mainly present as a monomer in a larger form termed "complex IVa". Since thermogenic tissue of Arum maculatum at the same time has high AOX and $\mathrm{I}+\mathrm{III}_{2}$ supercomplex abundance and activity, negative regulation of the alternative oxidase by supercomplex formation seems not to occur. Functional implications are discussed.
\end{abstract}


Abbreviations: AOX, Alternative Oxidase; OXPHOS, oxidative phosphorylation system; BN PAGE, blue native polyacrylamide gelelectrophoresis

Key words: Respiratory supercomplexes, oxidative phosphorylation, mitochondria, alternative oxidase, thermogenesis, Arum maculatum 


\section{INTRODUCTION}

Flowers of a group of monocotyledonous plants, mostly from the family Araceae, are able to regulate their flower temperature during flowering by active heat production [43]. Arum maculatum is a typical European example for a plant using thermogenesis for pollination. Plants of this family deceit insects by volatilization of odoriferous compounds similar to that of feces or urine emitted by the appendix. This simulates the natural insect laying sites. Insects are attracted and trapped in the floral chamber of the protogynous inflorescence. Fertile male and female flowers are enclosed in this floral chamber at the base of the spathe, which is closed at the top by fibrous sterile male flowers to bar insects from escaping. When female flowers become receptive, insects are simultaneously allured and fall into the chamber [14]. During the period of habitation in the floral chamber, insects may deposit pollen from other $A$. maculatum plants on the receptive stigma. This phase mostly ends the next day when the pollen matures. During this time, the sterile male flowers begin wilting, whereby the trapped flies are draped with pollen while escaping from the floral chamber. Thermogenesis seems to play different roles during this pollination process as demonstrated for Arum italicum and Arum maculatum: Four periods of heat are produced in the inflorescence: The first and the second heating event are not related to any insect attraction but responsible for unfolding the spathe and occur in the male flowers. A third heating event is produced by the appendix and enhances the vaporization of the volatile elements of the scent to attract pollinators. $[44,45])$. The last one is than produced by the stamens and seems to be responsible for the maturation of pollen $[2,14]$. In some species, heating often continues throughout the entire period of insect habitation and it is assumed that this may be related to the fact that insects require an elevated body temperature for activity. A warming floral environment may therefore be a significant energy reward for pollinators, enabling them to reduce the energy cost of their activity $[44,45]$.

Thermogenesis in Araceae is based on the mitochondrial respiratory chain. Like in other eukaryotes, the respiratory electron transfer chain of plant mitochondria is composed of four protein complexes localized in the inner mitochondrial membrane, the NADH dehydrogenase (complex I), the succinate dehydrogenase (complex II), the cytochrome c reductase (complex III) and the cytochrome c oxidase (complex IV). Additionally, two mobile electron transporters, ubiquinone and cytochrome c, are necessary for respiratory electron transport. All these components cooperate to transfer electrons form NADH or FADH 2 to molecular oxygen and thereby generate a proton gradient across the inner mitochondrial membrane. By the act of the ATP synthase complex, which also is termed complex V, the proton gradient is used for the generation of ATP from ADP. Besides complexes I to V, the mitochondria of plants include quite a number of additional, so-called "alternative" oxidoreductases, e.g. rotenone-insensitive alternative $\mathrm{NAD}(\mathrm{P}) \mathrm{H}$ dehydrogenases and a terminal oxidase called "alternative oxidase" (AOX) $[23,38,51]$. The latter competes with the complexes III and IV for electrons of the "ubiquinone pool" within the inner 
mitochondrial membrane. However, in contrast to complexes III and IV, AOX does not translocate protons across the inner mitochondrial membrane coupled to electron transfer. Instead, the redox energy is released as heat, which in the case of Araceae is used for the active regulation of pollination.

Hence, the respiratory electron transport chain of plant mitochondria is branched, with one branch contributing to the formation of a proton gradient across the inner mitochondrial membrane via complexes III and IV (and thereby to the formation of ATP), and another branch not contributing to the proton gradient but causing heat production via AOX. The regulation of electron partitioning between these two branches, which especially is important in thermogenic Arum species, so far not is completely understood [1, 23, 51]. AOX was found to be positively regulated by organic acids, especially pyruvate [28]. Furthermore, AOX can form homodimers via a disulfide bridge, which seems to (partially) deactivate the enzyme [49]. However, further mechanisms for AOX regulation most likely occur [47].

It recently was speculated that the formation of respiratory supercomplexes might indirectly affect AOX activity [12]. Respiratory supercomplexes were first described some years ago [41]. They are formed by defined interactions of the complexes I to IV (reviewed in [4]). Most stable are supercomplexes composed of complexes I+III $2, \mathrm{III}_{2}+\mathrm{IV}_{1-2}$ and $\mathrm{I}+\mathrm{III}_{2}+\mathrm{IV}_{1-4}[9,10,17,40]$. Formation of supercomplexes is believed to be dynamically regulated. Since the $\mathrm{I}+\mathrm{III}_{2}$ supercomplex most likely directly channels electrons from complex I to complex III2, its formation could restrict access of AOX to its substrate ubiquinol [12]. Hence, formation of the $\mathrm{I}+\mathrm{III}_{2}$ supercomplex possibly regulates AOX activity.

Here we report an investigation on the supramolecular structure of the respiratory chain of thermogenic Arum maculatum appendix mitochondria. As reported for other higher plants, respiratory supercomplexes can be detected upon mild solubilization of mitochondrial membranes in combination with analyses using blue native (BN) PAGE. The organization of the respiratory chain of Arum maculatum differs remarkably from the one of the model plant Arabidopsis thaliana. Functional implications for AOX regulation are discussed. 


\section{MATERIALS AND METHODS}

\subsection{Material}

Appendices of wild growing Arum maculatum plants were collected in the "Berggarten Hannover" during early spring (beginning of March till the end of April, 06:00 10:00am) from their natural environment. Classification of stages of inflorescence development was made according to James and Beevers [20] on the basis of physiological, morphological and odorous criteria.

\subsection{Isolation of mitochondria}

Mitochondria from Arum maculatum appendices were isolated as outlined before [37]. All steps were carried out at $4{ }^{\circ} \mathrm{C}$. Arum maculatum appendices were cut in small pieces of approximately $0.5 \mathrm{~cm}$ and homogenized in a Warring blender ( 3 x $20 \mathrm{sec}$ full speed) in grinding medium containing 0.3 M mannitol, $0.2 \mathrm{mM}$ EDTA, $20 \mathrm{mM}$ MOPS, $0.2 \%(\mathrm{w} / \mathrm{v})$ BSA, $2 \mathrm{mM}$ pyruvate, $7 \mathrm{mM}$ cysteine ( $\mathrm{pH}$ 7.5). In a following step, the homogenate was additionally ground two times with a mortar and than filtered by the use of a gaze. Afterwards, the $\mathrm{pH}$ was re-adjusted to 7.5. Mitochondria were separated from other cell components by several steps of differential centrifugation and finally purified by Percoll gradient density ultracentrifugation as outlined in Werhahn et al. [54] for Arabidopsis thaliana. The mitochondrial bands were washed several times in "washing buffer" containing 0.3 M mannitol, $0.2 \mathrm{mM}$ EDTA, $20 \mathrm{mM}$ MOPS, 0.2\% (w/v) BSA, $2 \mathrm{mM}$ pyruvate (pH 7.5) and either directly used for $\mathrm{O}_{2}$ electrode measurements or stored at $-80^{\circ} \mathrm{C}$ at a concentration of $0.1 \mathrm{~g}$ of mitochondria per $\mathrm{ml}$ "washing buffer" for further investigations. Mitochondria from Arabidopsis thaliana suspension cell cultures were prepared as outlined in Werhahn et al. [54] with the following modifications: The cultivation medium was composed of $3 \%$ sucrose (w/v), Gamborg B5 medium including vitamins (Duchefa, The Netherlands), 2,4dichlorphenoxyacetic acid $\left(1 \mathrm{mg} \mathrm{L}^{-1}\right)$, kinetin $\left(0,1 \mathrm{mgL}^{-1}\right)$ and ampicilline $\left(100 \mathrm{mg} \mathrm{L}^{-1}\right)$.

\subsection{Oxygen electrode measurements}

Oxygen consumption of isolated Arum maculatum appendix mitochondria (developmental stages $\beta, \gamma$ and $\delta$ ) was measured in a Clark-type oxygen electrode with a reaction chamber volume of $2 \mathrm{ml}$ (Oxygraph, Hansatech, Norfolk, UK). Standard experiments were carried out using $1 \mathrm{mg}$ of mitochondria in "reaction buffer" $(0.3 \mathrm{M}$ mannitol, $10 \mathrm{mM}$ $\mathrm{K}_{2} \mathrm{HPO}_{4}, 10 \mathrm{mM} \mathrm{KCl}, 5 \mathrm{mM} \mathrm{MgCl}(\mathrm{pH} 7.2)$ ) by successive addition of succinate, ADP, KCN and SHAM. Oxygen consumption was calculated in nmol $\Delta \mathrm{O}_{2} \mathrm{~min}^{-1} \mathrm{mg}_{\text {protein }}^{-1}$ [13]. 


\subsection{Gel electrophoresis procedures}

The OXPHOS system of isolated mitochondria was analysed by $1 \mathrm{D}$ blue native (BN) PAGE and 2D BN / SDS PAGE according to Wittig et al. [55]. 1D SDS PAGE was carried out as described by Schägger and von Jagow [42]. Solubilization of mitochondrial protein was performed using digitonin at a concentration of $5 \mathrm{~g} / \mathrm{g}$ mitochondrial protein [12].

\subsection{Gel staining procedures}

All gels were either stained with Coomassie colloidal [30, 31] or silver [18]. In-gel enzyme activity staining for mitochondrial respiratory complexes I, II and IV were carried out as described in Zerbetto et al. [56] and Jung et al. [22].

\subsection{Western Blotting}

Proteins separated on polyacrylamide gels were blotted onto nitrocellulose membranes for antibody staining using the Trans Blot Cell from BioRad (Munich, Germany). Blotting was carried out as described in Kruft et al. [25]. Immune stainings were performed using the VectaStain ABC Kit (Vector Laboratories, Burlingame, CA, US). The AOX antibody used in all experiments was provided by Tom Elthon, University of Nebraska, US. It is a monoclonal antibody directed against AOX from Sauromatum guttatum (voodoo lily) which also specifically recognizes AOX from Arum, Amorphophallus and Symplocarpus as shown previously by Elthon et al. 1989 [11].

\subsection{Tryptic digestion of proteins for subsequent analysis by mass spectrometry}

Protein spots were cut from a BN-SDS gel and de-stained in water. Gel pieces were dehydrated using acetonitrile. This treatment was repeated after each step of the protocol. For carbamidomethylization, gel pieces were first incubated in $20 \mathrm{mM}$ DTT for 30 minutes at $56^{\circ} \mathrm{C}$ and then incubated in $55 \mathrm{mM}$ iodacetamide at room temperature for the same time in the dark. The dehydrated gel pieces were incubated in $0.1 \mathrm{M} \mathrm{NH}_{4} \mathrm{HCO}_{3}$ and digestion was carried out at $37^{\circ} \mathrm{C}$ and overnight using trypsin $(2 \mu \mathrm{g} / \mathrm{ml}$ Resuspension buffer [Promega, Mannheim, Germany] in $0.1 \mathrm{M} \mathrm{NH}_{4} \mathrm{HCO}_{3}$ ). Digestion was stopped the next day and peptides were extracted by incubation with acetonitrile for 15 minutes at $37^{\circ} \mathrm{C}$. Supernatants were kept and basic peptides were extracted using $5 \% \mathrm{HCOOH}$. After incubation for 15 minutes at $37^{\circ} \mathrm{C}$ the dehydration step was repeated and the supernatant was combined with the first one. Protein fractions were finally dried via vacuum centrifugation, resuspended in $2 \%$ methanol, $0.5 \%$ $\mathrm{HCOOH}$ and stored at $-20^{\circ} \mathrm{C}$.

\subsection{Protein identification by mass spectrometry}


Samples were reconstituted into $20 \mu \mathrm{l}$ of loading buffer ( $2 \%$ acetonitrile ACN (v/v) vs $0.5 \%(\mathrm{v} / \mathrm{v})$ formic acid) and analyzed by liquid chromatography/tandem mass spectrometry. Digest peptides were concentrated and desalted on a C18 trap column (PepMap C18, Dionex, Idstein, Germany) using a Tempo 1D nanoLC system (Applied Biosystems, Foster City, California, U.S.A.). Peptide separation was achieved on a reversed phase $\mathrm{C} 18$ column (PepMap C18, $75 \mu \mathrm{m}$ i.d., $15 \mathrm{~cm}$, Dionex) using a 25 min linear gradient of 5-35\% (v/v) ACN versus $0.1 \%(\mathrm{v} / \mathrm{v})$ aqueous formic acid. The eluent was analyzed on hybrid triple quadrupole/linear ion trap mass spectrometer (4000 Q TRAP LC/MS/MS System, Applied Biosystems) equipped with a heated Desolvation Chamber Interface set to $150{ }^{\circ} \mathrm{C}$ and operated under Analyst 1.5 software. Up to five peptide precursor ions detected by a linear ion trap MS scan were first subjected to a high resolution MS scan to determine charge state and molecular weight. Suitable precursors were then fragmented by Enhanced Product Ion Scans. The resulting spectra have been shown to be suitable for de novo sequence analysis [21]. The average cycle time for this experiment was $4.2 \mathrm{~s}$.

\subsection{Identification of proteins from $\mathrm{LC} / \mathrm{MS} / \mathrm{MS}$ data.}

Protein identifications were carried out using the ProteinPilot Software V2.0.1 (Applied Biosystems, Foster City, California, U.S.A.) against an A. thaliana protein sequence database (tair 8 release, www.arabidopsis.org). ProteinPilot allows identification of proteins from organisms without a strong genomic sequence background by matching data to the genome sequence of a related organism. The software is based on algorithms tolerating nontryptic cleavages as well as amino acid substitutions according to probability criteria $[46,50]$. 


\section{RESULTS}

Mitochondria were isolated from the developmental stages $\beta, \gamma$ and $\delta$ of Arum maculatum appendices and from Arabidopsis thaliana suspension cell cultures as a control. Classification of the developmental stages was carried out according to James and Beevers 1950 who described six stages during the development of Arum maculatum inflorescences: from the $\alpha$ stage, in which the inflorescence is just developing and the spathe is tightly folded to the $\zeta$ stage were the inflorescence is entirely wilting. It was reported that thermogenesis has its peak in the gamma stage and slows down at the end of the delta stage, although the extent and timing of thermogenesis varies considerably [20,37]. During the preparation of spadices of the gamma and delta stage, the typical urine-like scent was detectable as well as the release of various insects from the floral chamber. These observations are due to the heating phase of the appendix (third heating event) when the urine-like scent is dispersed to attract pollinators $[3,14]$. The classification of the developmental stages of appendices used for mitochondrial isolations for the experiments described below took place on basis of morphological, physiological and odorous criteria.

To evaluate the intactness and purity of isolated mitochondria, oxygen consumption of organelle fractions from $A$. maculatum and A. thaliana was analyzed with a Clark-type oxygen electrode. Using succinate as a substrate, state II respiration was high in Arum maculatum ( $>400 \mathrm{nmol} \mathrm{O}_{2} / \mathrm{min} / \mathrm{mg}$ protein) and further increased significantly after ADP addition (700 $\mathrm{nmol} \mathrm{O}_{2} \mathrm{~min}^{-1} \mathrm{mg}$ protein ${ }^{-1}$ ), indicating good intactness of the isolated mitochondria (data not shown). Addition of $\mathrm{KCN}$ inhibited respiration by about $50 \%$; further addition of SHAM nearly completely blocked respiration. Even higher inhibition of respiration by $\mathrm{KCN}$ was previously reported for A. maculatum mitochondria isolated from $\beta$ to $\delta$ stages $[36,37,52,53]$. However, our experiments were carried out using only succinate as a substrate and no additional substrates like malate or pyruvate which are known to activate AOX.

In contrast, respiration of mitochondria purified from Arabidopsis thaliana suspension cell cultures exhibited a significantly lower state II and III respiration which is in line with data reported in the literature $[8,13,26]$. KCN addition nearly completely inhibited oxygen consumption, indicating that alternative respiration is very low. We conclude that mitochondrial fractions from both organisms are of good quality and suitable for further investigations on the Oxidative Phosphorylation (OXPHOS) system.

\subsection{Characterization of the OXPHOS system of Arum maculatum appendix mitochondria}

To characterize the composition of the OXPHOS complexes of Arum maculatum, appendix mitochondria of the developmental stages $\beta, \gamma$ and $\delta$ were solubilized with $5 \mathrm{~g} / \mathrm{g}$

digitonin and proteins were resolved on one dimensional blue native (BN) gels (Figure 1). As 
a control, A. thaliana mitochondria were resolved on the same gel. Overall, occurrence of OXPHOS complexes is similar in A. maculatum and A. thaliana. However, the band corresponding to mitochondrial complex I is completely absent in A. maculatum. It previously was reported that mitochondrial complex I partly forms part of the $1500 \mathrm{kDa} \mathrm{I}+\mathrm{III}_{2}$ supercomplex in A. thaliana [12]. An in-gel NADH dehydrogenase activity stain was carried out to search for complex I of A. maculatum on the BN gel (Figure 1). Indeed, activity is clearly visible in the $1500 \mathrm{kDa}$ range for $A$. maculatum like it is in A. thaliana. Furthermore, some activity is observed in the low molecular mass range of the gel, which probably is due to the presence of one of the alternative $\mathrm{NAD}(\mathrm{P}) \mathrm{H}$ dehydrogenases. Complex II was detected by another in-gel activity stain (Figure 1). It is of comparable activity in $A$. thaliana and $A$. maculatum. However, for unknown reasons, it has a much smaller molecular mass in $A$. maculatum. Instead, some especially large versions of complex II were detected by the activity stain in $A$. maculatum at very low abundance, which might represent complex II containing supercomplexes. Finally, complex IV was detected on the 1D BN gel by an in-gel activity stain. It was found for $A$. thaliana that this complex is present in a larger and smaller version termed complex IVa and complex IVb [12]. The smaller version is much more abundant in A. thaliana and lacks at least one subunit, which is homologous to the Cox VIb protein of other groups of organism. A. maculatum mitochondria also include the two versions of complex IV. However, in contrast to $A$. thaliana, the larger version of this complex is clearly more abundant. Furthermore, the complex IV in- gel activity stain allows visualization of complex IV containing supercomplexes which are absent in $A$. thaliana but which were reported for potato and spinach $[13,24]$. In potato, complex IV can associate with dimeric complex III forming $\mathrm{III}_{2}+\mathrm{IV}_{1-2}$ supercomplexes of about 700-800 kDa. Furthermore, complex I can be bound to the complexes $\mathrm{III}_{2}$ and IV forming $\mathrm{I}+\mathrm{III}_{2}+\mathrm{IV}_{1-4}$ supercomplexes, which run above the $\mathrm{I}+\mathrm{III}_{2}$ supercomplex in the $>1700 \mathrm{kDa}$ range. In accordance with the data reported for potato, complex IV in-gel activity stain reveals signals in the regions of both the $\mathrm{III}_{2}+\mathrm{IV}_{1}$ and the $\mathrm{I}^{+} \mathrm{III}_{2}+\mathrm{IV}_{1}$ supercomplexes on the $\mathrm{BN}$ gel for $A$. maculatum. The complexes $\mathrm{III}_{2}(500$ $\mathrm{kDa})$ and $\underline{\mathrm{V}}(550 \mathrm{kDa})$ have similar sizes in A. maculatum and A. thaliana. In addition, abundances of these complexes are comparable in the two organisms.

To further investigate the OXPHOS system in A. maculatum, 2D BN/SDS PAGE was carried out for separating the subunits of the resolved protein complexes. A. thaliana mitochondria were resolved on a parallel 2D gel to allow identification of protein complexes from A. maculatum on the basis of subunit composition. Indeed, subunits of A. maculatum complex I are completely absent in the gel region normally covered by the monomeric form of this complex (Figure 2). Instead, all complex I subunits co-migrate with the subunits of complex $\mathrm{III}_{2}$ and therefore form part of the $\mathrm{I}+\mathrm{III}_{2}$ supercomplex. Complex II has a very unusual subunit composition in most investigated plants because it is composed of eight distinct subunits, whereas complex II of all other investigated groups of organisms only includes four subunits [12, 29]. In A. maculatum, the large eight subunit complex is not detectable on the 2D gels (Figure 2). Instead, a smaller four subunit complex is visible which 
runs further to the right on the $2 \mathrm{D}$ gel. It currently can not be decided if the lacking subunits are absent in $A$. maculatum or if they get detached from the complex during electrophoresis. No complex II subunits forming part of supercomplexes could be found in both species. Like in A. thaliana, the larger version of complex IV includes an additional subunit in the $30 \mathrm{kDa}$ range, which is absent in the smaller version and probably corresponds to the Cox VIb subunit of other organisms. Overall, complex IV in Arum maculatum mitochondria is of comparatively high abundance. Complexes $\mathrm{III}_{2}$ and $\mathrm{V}$ differ slightly in subunit composition between $A$. maculatum and $A$. thaliana. Therefore, identities of the subunits of the $A$. maculatum complexes are not simply deducible from their gel positions in comparison to $A$. thaliana but rather should be uncovered by mass spectrometry. In A. thaliana, some complex $\mathrm{V}$ subunits not only are visible in the gel region corresponding to $550 \mathrm{kDa}$ on the $1 \mathrm{D}$ gel, but additionally in the $350 \mathrm{kDa}$ range. This phenomenon is due to a partial dissection of the $\mathrm{F}_{1}$ and $\mathrm{F}_{0}$ parts of this protein complex, the latter of which completely gets dissected as described before [20]. In contrast, no $\mathrm{F}_{1}$ subcomplex is visible in A. maculatum on the 2D BN / SDS gels (Figure 2). This reflects a high degree of intactness of the protein complexes isolated from the mitochondria of this organism.

Comparison of the 2D BN/SDS gel of A. maculatum mitochondria (Figure 2) with the well investigated mitochondrial proteome of $A$. thaliana, rice or potato resolved by the same gel system [e.g. 6, 12,15] reveals some additional protein spots of unknown identity. Corresponding proteins do not form part of OXPHOS complexes. Identifications by mass spectrometry revealed complexes comprising malic enzyme $(\sim 400 \mathrm{kDa})$, glutamate dehydrogenase $(\sim 250 \mathrm{kDa})$, the adenine nucleotide translocase and porin (both at $\sim 250 \mathrm{kDa}$ ), the pyruvate dehydrogenase beta subunit, a nucleoside diphosphate kinase and HSP10 (both in the $150 \mathrm{kDa}$ range) and the superoxide dismutase (Figure 3, Table I).

\subsection{Carbonic anhydrase domain of complex I in A. maculatum and A. thaliana}

Complex I in monomeric state is especially large in plant cells and consequently itself can be designated a "supramolecular" structure. Its properties therefore were also investigated in A. maculatum. In Arabidopsis, complex I is known to include quite a number of additional plant-specific subunits [16]. Most notably, a group of 3-5 structurally related $30 \mathrm{kDa}$ proteins occurs which show high sequence similarity to $\gamma$-type carbonic anhydrases $[32-35,48]$. The carbonic anhydrases form part of a unique extra spherical domain attached to the membrane arm of complex I on its matrix-exposed side [9, 35, 48]. The physiological role of this extra domain is unknown but hypothesized to be important in the context of an inner-cellular $\mathrm{CO}_{2}$ transfer mechanism to supply the Calvin cycle of the chloroplast with $\mathrm{CO}_{2}$ liberated in mitochondria due to the decarboxylation of organic acids or glycine [5]. Presence of carbonic anhydrase subunits was also reported for rice, Chlamydomonas and Zea maize [7, 16, 35, 48]. Occurrence of the carbonic anhydrase subunits in A. maculatum was addressed by Western blotting using 2D BN/SDS gels (Figure 4). An immuno-positive subunit clearly forms part of 
the $\mathrm{I}+\mathrm{III}_{2}$ supercomplex. It currently can not be decided whether the complex includes different forms of this protein as reported for $A$. thaliana. In contrast, the immune signal is present at more than two positions on the control blot for A. thaliana, which represents the $\mathrm{I}+\mathrm{III}_{2}$ supercomplex bound form, the complex I bound form and some smaller forms most likely representing subcomplexes of complex I [34]. Absence of the complex I subcomplexes further confirms the high degree of intactness of the protein complexes isolated from $A$. maculatum mitochondria.

\subsection{Alternative oxidase in Arum maculatum and Arabidopsis thaliana}

Alternative oxidase does not form part of OXPHOS protein complexes or supercomplexes in A. thaliana [12] and is difficult to detect on Coomassie-stained 2D BN/SDS gels. Therefore, the AOX protein was immunologically detected for A. thaliana and A. maculatum mitochondria using 1D SDS-PAGE and Western blotting (Figure 5). In correspondence with published experimental results, AOX represents a very abundant $30 \mathrm{kDa}$ protein in A. maculatum. In contrast, AOX was hardly detectable in A. thaliana mitochondria isolated from suspension cell cultures. This is inline with the low AOX activity detectable by $\mathrm{O}_{2}$ consumption measurements. To test whether AOX might be associated with OXPHOS complexes in Arum maculatum, the enzyme was immunologically detected after protein separation by 2D BN/SDS PAGE (Figure 6). AOX clearly gives a signal in a gel region corresponding to the $<50 \mathrm{kDa}$ range on the corresponding 1D BN gel and therefore seems not to be associated with any of the larger complexes. 


\section{DISCUSSION}

This study reports an investigation of the supramolecular structure and subunit composition of the OXPHOS system in A. maculatum using mild protein solubilization with digitonin and protein separation by BN-PAGE. The organization of the OXPHOS system in A. maculatum clearly differs with respect to the one of the model plant $A$. thaliana: (i) Singular complex I is absent (ii) the I+ $\mathrm{III}_{2}$ supercomplex is very abundant, (iii) the complex II has fewer subunits , complex IV is most abundant in its larger form termed "complex IVa" and (v) complexes $\mathrm{III}_{2}$ and $\mathrm{V}$ also differ with respect to subunit composition. Some small amounts of III $+\mathrm{IV}$ and $\mathrm{I}+\mathrm{III}_{2}+\mathrm{IV}$ supercomplexes are detectable in $A$. maculatum but not in $A$. thaliana. In both organisms, AOX is not attached to any of the OXPHOS complexes or supercomplexes. To evaluate whether the organization of the OXPHOS system varies between the different developmental stages of appendices, mitochondria were isolated from $\beta$, $\gamma$ and $\delta$ stages. However, significant differences between these stages were not observed. This result partially could be due to difficulties in precisely classifying the different stages of inflorescence development. Nonetheless, differences at least should be visible between the $\beta$ and $\delta$ stages. Since this is not the case we conclude that the organization of the OXPHOS system during inflorescence development has to be considered as rather stable. In-gel enzyme activity stainings reveal that OXPHOS complexes remain active through the investigated stages. However, these results have to be taken with caution because activity assays carried out in gels not necessarily reflect the corresponding in vivo activities. It is still a matter of debate, how electron transfer through the highly branched OXPHOS system is regulated.

It was previously reported that alternative respiration by far exceeds "normal" respiration (cytochrome-pathway respiration involving the complexes III and IV) during thermogenesis in A. maculatum. However, varying values were reported for the ratio of alternative versus cytochrome-mediated respiration during appendix development [36, 53]. Values seem to depend on experimental conditions, e.g. presence of pyruvate during $\mathrm{O}_{2}$ consumption measurements of isolated organelles. Furthermore, the ratio of alternative versus cytochrome-mediated respiration might depend on cultivation conditions of Arum during flowering (green house or field experiment, external temperature etc). In our investigation, alternative respiration was substantial but at the same time abundance and activity of the classical OXPHOS complexes was high. Indeed, activities of the OXPHOS complexes are comparable to the activity of the same complexes in A. thaliana. Obviously, besides high AOX activity for thermogenesis, "normal" respiratory activity is important for ATP generation which is needed to power various biochemical processes during inflorescence development. Large amounts of substrates must be imported into mitochondria during flowering of $A$. maculatum to power the two highly active branches of the respiratory electron transport chain. Partially, ATP might be also generated within mitochondria by the act of nucleoside diphosphate kinases, which were found to be of very high abundance in appendix mitochondria (Figure 3). 
Many studies have been performed to understand AOX regulation. Besides substrate activation by pyruvate, redox regulation is considered to be important for AOX activity. AOX forms a dimer via a covalent Cys-Cys bridge which inactivates the protein. Furthermore, it recently was suggested that supercomplex formation of complexes I and $\mathrm{III}_{2}$ might indirectly regulate alternative respiration because it could restrict access of AOX towards its substrate ubiquinol [12]. This would indicate that tissues exhibiting high alternative respiration should have a decreased abundance of the $\mathrm{I}+\mathrm{III}_{2}$ supercomplex. However, this clearly is not the case in A. maculatum. The appendix mitochondria are highly active with respect to alternative respiration, but at the same time have a very high abundance of this supercomplex. In fact, momomeric complex I is completely absent in A. maculatum miochondria. We conclude that supercomplex formation most likely does not affect AOX activity. This possibly could mean that electrons are not directly channeled between complex I and complex $\mathrm{III}_{2}$ within the supercomplex. Although flux control experiments rather support electron channeling within the supercomplex [27], direct proof so far has not been provided. Indeed, recent x-ray structural data for the peripheral arm of complex I [39] and single particle EM data for the $\mathrm{I}+\mathrm{III}_{2}$ supercomplex [9] indicate that the ubiquinone reduction and ubiquinol oxidation sites within the supercomplex are in proximity but probably not in direct contact. Therefore, the physiological role of the $\mathrm{I}+\mathrm{III}_{2}$ supercomplex during respiration and thermogenesis remains partially elusive and should be further addressed by future research. 


\section{ACKNOWLEDGEMENTS}

We thank the "Berggarten" in Hannover, Germany, for providing Arum maculatum. Furthermore, we wish to thank Tom Elton, University of Nebraska, USA, for providing the antibodies directed against the AOX. This research was supported by the Deutsche Forschungsgemeinschaft (grants Br 1829/7-3 and Br 1829/8-1). 


\section{REFERENCES}

[1] Affourtit C., Albury M.S., Crichton P.G., Moore A.L., Exploring the molecular nature of alternative oxidase regulation and catalysis, FEBS Lett. 510 (2002) 121-126.

[2] Albre J., Quilichini A., Gibernau M., Pollination ecology of Arum italicum (Araceae), Bot. J. Linn. Soc. 141 (2003) 205-214.

[3] Bermadinger-Stabentheiner E., Stabentheiner A., Dynamics of thermogenesis and structure of epidermal tissue in the inflorescences of Arum maculatum, New Phytol. 131 (1995) 41-50.

[4] Boekema E.J., Braun H.P., Supramolecular structure of the mitochondrial oxidative phosphorylation system, J. Biol. Chem. 282 (2007) 1-4.

[5] Braun H.P., Zabaleta E., Carbonic anhydrase subunits of the mitochondrial NADH dehydrogenase complex (complex I) in plants, Physiol. Plant. 129 (2007) 114-122.

[6] Bykova N.V., Egsgaard H., Moller I.M., Identification of 14 new phosphoproteins involved in important plant mitochondrial processes, FEBS Lett. 540 (2003)141-146.

[7] Cardol P., Vanrobaeys F., Devreese B., Van Beeumen J., Matagne R.F., Remacle C., Higher plant-like subunit composition of mitochondrial complex I from Chlamydomonas reinhardtii: 31 conserved components among eukaryotes, Biochim. Biophys. Acta 1658 (2004) 212-224.

[8] De Virville J.D., Alin M.F., Aaron Y., Rémy R., Guillot-Salomon T., Cantrel C., Changes in functional properties of mitochondria during growth cycle of Arabidopsis thaliana cell suspension cultures, Plant Physiol. Biochem. 36 (1998) 347-356.

[9] Dudkina N.V., Eubel H., Keegstra W., Boekema E.J., Braun H.P., Structure of a mitochondrial supercomplex formed by respiratory-chain complexes I and III, Proc. Natl. Acad. Sci. USA 102 (2005) 3225-3229.

[10] Dukina N.V., Sunderhaus S., Boekema E.J., Braun H.P., The higher level of the oxidative phosphorylation system: mitochondrial supercomplexes, J. Bioenerg. Biomembr. 40 (2008) 419-424.

[11] Elthon TE, Nickels RL, McIntosh L., Monoclonal antibodies to the alternative oxidase of higher plant mitochondria. Plant Physiol. 89 (1989) 1311-1317.

[12] Eubel H., Jänsch L., Braun H.P., New insights into the respiratory chain of plant mitochondria. Supercomplexes and a unique composition of complex II, Plant Physiol. 133 (2003) 274-286.

[13] Eubel H., Heinemeyer J., Braun H.P., Identification and characterization of respirasomes in potato mitochondria, Plant Physiol. 134 (2004)1450-1459.

[14] Gibernau M., Macquart D., Przetak G., Pollination in the genus Arum - a review, Aroideana 27 (2004) 148-166.

[15] Heazlewood J.L., Howell K.A., Whelan J., Millar A.H., Towards an analysis of the rice mitochondrial proteome, Plant Physiol. 132 (2003) 230-242. 
[16] Heazlewood J.L., Howell K.A., Millar A.H., Mitochondrial complex I from Arabidopsis and rice: orthologs of mammalian and fungal components coupled with plant specific subunits, Biochim. Biophys. Acta 1604 (2003) 159-169.

[17] Heinemeyer J., Braun H.P., Boekema E.J., Kouril R., A structural model of the cytochrome c reductase/oxidase supercomplex from yeast mitochondria, J. Biol. Chem. 282 (2007) 12240-12248.

[18] Heukeshoven J., Dernick R., In: Radula, B (Ed) Electrophoresis Forum 1986, Technische Universität München, (1986) 22-27.

[19] Jänsch L., Kruft V., Schmitz U.K., Braun H.P., New insights into the composition, molecular mass and stoichiometry of the protein complexes of plant mitochondria, Plant J. 9 (1996) 357-368.

[20] James W.O., Beevers H., The respiration of Arum spadix. A rapid respiration, resistant to cyanide, New Phytol. 49 (1950) 353-374.

[21] Jorge I., Navarro R.M., Lenz C., Ariza D., Porras C., Jorrín J., The Holm Oak leaf proteome: Analytical and biological variability in the protein expression level assessed by 2$\mathrm{DE}$ and protein identification tandem mass spectrometry de novo sequencing and sequence similarity searching, Proteomics 5 (2005) 222-234.

[22] Jung C., Higgins C.M.J., Xu Z., Measuring the quantity and activity of mitochondrial electron transport chain complexes in tissues of central nervous system using blue native polyacrylamid gel electrophoresis, Anal. Biochem. 286 (2000) 214-223.

[23] Juszczuk I.M., Rychter A.M., Alternative Oxidase in higher Plants, Acta. Biochim. Polonica 50 (2003) 1257-1271.

[24] Krause F., Reifschneider N.H., Vocke D., Seelert H., Rexroth S., Dencher N.A.,

"Respirasome"-like supercomplexes in green leaf mitochondria of spinach, J. Biol. Chem. 279 (2004) 48369-48375.

[25] Kruft V., Eubel H., Werhahn W., Jänsch L., Braun H.P., Proteomic approach to identify novel mitochondrial functions in Arabidopsis thaliana, Plant Physiol. 127 (2001) 1694-1710. [26] Lee C.P., Eubel H., O'Toole N., Millar A.H., Heterogeneity of the mitochondrial proteome for photosynthetic and non-photosynthetic Arabidopsis metabolism, Mol. Cell. Proteomics 7 (2008) 1297-1316.

[27] Lenaz G., Genova M.L., Structural and functional organization of the mitochondrial respiratory chain: a dynamic super-assembly, Int. J. Biochem Cell Biol. 41 (2009) 1750-1772. [28] Millar A.H., Wiskich .JT., Whelan J., Day D.A., Organic acid activation of the alternative oxidase of plant mitochondria, FEBS Lett. 329 (1993) 259-262.

[29] Millar A.H., Eubel H., Jänsch L., Kruft V., Heazlewood J.L., Braun H.P., Mitochondrial cytochrome c oxidase and succinate dehydrogenase complexes contain plant specific subunits, Plant Mol. Biol. 56 (2004) 77-90.

[30] Neuhoff V., Stamm R., Eibl H., Clear background and highly sensitive protein staining with Coomassie Blue dyes in polyacrylamide gels: A systematic analysis, Electrophoresis 6 (1985) 427-448. 
[31] Neuhoff V., Stamm R., Pardowitz I., Arold N., Ehrhardt W., Taube D., Essential problems in quantification of proteins following colloidal staining with Coomassie Brilliant Blue dyes in polyacrylamide gels, and their solution, Electrophoresis 11 (1990) 101-117. [32] Parisi G., Perales M., Fornasari M.S., Colaneri A., Gonzalez-Schain N., Gomez-Casati D., Zimmermann S., Brennicke A., Araya A., Ferry J.G., Echave J., Zabaleta E., Gamma carbonic anhydrases in plant mitochondria, Plant Mol. Biol .55 (2004) 192-207.

[33] Perales M., Parisi G., Fornasari M.S., Colaneri A., Villareal F., Gonzalez-Schain N., Echave J., Gomez-Casati D., Braun H.P., Araya A., Zabaleta E., Gamma carbonic anhydrase like complex interact with plant mitochondrial complex I, Plant Mol. Biol. 56 (2004) 947957.

[34] Perales M., Eubel H., Heinemeyer J., Colaneri A., Zabaleta E., Braun H.P., Disruption of a nuclear gene encoding a mitochondrial gamma-type carbonic anhydrase reduces complex I and supercomplex $\mathrm{I}+\mathrm{III}_{2}$ levels and alters mitochondrial physiology in Arabidopsis, J. Mol. Biol. 350 (2005) 263-277.

[35] Peters K., Dudkina N.V., Jänsch L., Braun H.P., Boekema E.J., A structural investigation of complex I and $\mathrm{I}+\mathrm{III}_{2}$ supercomplex from Zea mays at $11-13 \AA$ resolution: assignment of the carbonic anhydrase domain and evidence for structural heterogeneity within complex I, Biochim. Biophys. Acta 1777 (2008) 84-93.

[36] Petrussa E., Casolo V., Peresson C., Krajňáková J., Macrì F., Vianello A., Activity of a $\mathrm{K}^{+}{ }_{\text {ATP }}$ channel in Arum spadix mitochondria during thermogenesis, J. Plant Phys. 165 (2008) 1360-1369.

[37] Proudlove M.O., Beechey R.B., Moore A.L., Pyruvate transport by thermogenic-tissue mitochondria, Biochem. J. 247 (1987) 441-447.

[38] Rasmusson A.G., Geisler D.A., Møller I.M., The multiplicity of dehydrogenases in the electron transport chain of plant mitochondria. Mitochondrion 8 (2008) 47-60.

[39] Sazanov L.A., Hinchliffe P., Structure of the hydrophilic domain of respiratory complex I from Thermus thermophilus, Science 311 (2006) 1430-1436.

[40] Schäfer E., Seelert H., Reifschneider N.H., Krause F., Dencher N.A., Vonck J., Architecture of active mammalian respiratory chain supercomplexes, J. Biol. Chem. 281 (2006) 15370-15375.

[41] Schägger H., Pfeiffer K., Supercomplexes in the respiratory chains of yeast and mammalian mitochondria, EMBO J. 19 (2000) 1777-1783.

[42] Schägger H., Jagow G., Tricine-sodium dodecyl sulfate-polyacrylamide gel electrophoresis for the separation of proteins in the range from 1 to $100 \mathrm{kDa}$, Anal. Biochem. 166 (1987) 368-379.

[43] Seymour R.S., Biophysics and physiology of temperature regulation in thermogenic flowers, Bioscience Reports 21 (2001) 223-236.

[44] Seymour R.S., Gibernau M., Ito K., Thermogenesis and respiration of inflorescences of the dead horse arum Helicodiceros muscivorus, a pseudothermoregulatory aroid associated with fly pollination, Functional ecology 17 (2003a) 886 - 894. 
[45] Seymour R.S., White C.R., Gibernau M., Heat reward for insect pollinators, Nature 426 (2003b) 243-244.

[46] Shilov I.V., Seymour S.L., Patel A.A., Loboda A., Tang W.H., Keating S.P., Hunter C.L., Nuwaysir L.M., Schaeffer D.A., The paragon algorithm: A next generation search engine that uses sequence temperature values and feature probabilities to identify peptides from tandem mass spectra, Mol. Cell. Proteomics 6 (2007) 1638-1655.

[47] Siedow J.N., Umbach A.L., The mitochondrial cyanide resistant oxidase: structural conservation amid regulatory diversity, Biochim. Biophys. Acta 1459 (2000) 432-439. [48] Sunderhaus S., Dudkina N.V., Jänsch L., Klodmann J., Heinemeyer J., Perales M., Zabaleta E., Boekema E.J., Braun H.P., Carbonic anhydrase subunits form a matrix exposed domain attached to the membrane arm of mitochondrial complex I in plants, J. Biol. Chem. 281 (2006) 6482-6488.

[49] Umbach A.L., Siedow J.N., Covalent and non-covalent dimers of the cyanide-resistant alternatice oxidase protein in higher plant mitochondria and their relationship to enzyme activity. Plant Physiol. 103 (1993) 845-854.

[50] Valledor L., Castillejo M.A., Lenz C., Rodriguez R., Cañal M.J., Jorrín J., Proteomic analysis of Pinus radiata needles: 2-DE map and protein identification by LC/MS/MS and substitution-tolerant database searching, J. Proteome Res. 7 (2008) 2616-2631.

[51] Vanlerberghe G.C., McIntosh L., Alternative Oxidase: From gene to function, Annu. Rev. Plant Physiol. Plant Mol. Biol. 48 (1997) 703-734.

[52] Wagner A.M., Wagner M.J., Moore A.L., In vivo ubiquinone reduction levels during Thermogenesis in Araceae, Plant Physiol. 117 (1998) 1501-1506.

[53] Wagner A.M., Krab K., Wagner M.J., Moore A.L., Regulation of thermogenesis in flowering Araceae: The role of the alternative oxidase, Biochim. Biophys. Acta 1777 (2008) 993-1000.

[54] Werhahn W., Niemeyer A., Jänsch L., Kruft V., Schmitz U.K., Braun H.P., Purification and characterization of the preprotein translocase of the outer mitochondrial membrane from Arabidopsis thaliana: identification of multiple forms of TOM20, Plant Physiol. 125 (2001) 943-954.

[55] Wittig I., Braun H.P., Schägger H., Blue native PAGE, Nat. Protocols 1 (2006) 418-428. [56] Zerbetto E., Verqani L., Dabbeni-Sala F., Quantification of muscle mitochondria oxidative phosphorylation enzymes via histochemical staining of blue native polyacrylamide gels, Electrophoresis 18 (1997) 2059-2064. 
Table I: Identified proteins of mitochondria from Arum maculatum

\begin{tabular}{|c|c|c|c|c|c|c|}
\hline $\operatorname{Spot}^{1}$ & Protein identity $^{2}$ & $\begin{array}{l}\text { AGI } \\
\text { accession } \\
\text { number }^{3}\end{array}$ & $\begin{array}{l}\text { Calculated } \\
\text { molecular } \\
\text { mass } \\
{[\mathrm{kDa}]} \\
\end{array}$ & $\begin{array}{l}\text { GRAVY } \\
\text { score }\end{array}$ & Score $^{4}$ & $\begin{array}{l}\text { Coverage } \\
{[\%]^{5}}\end{array}$ \\
\hline \multirow[t]{2}{*}{1} & Malate oxidoreductase (Malic enzyme) & At4g00570 & 66.64 & -0.092 & 34.13 & 58.6 \\
\hline & Malate oxidoreductase (Malic enzyme) & At2g13560 & 69.66 & -0.235 & 32.31 & 61.5 \\
\hline \multirow[t]{3}{*}{2} & Glutamate dehydrogenase 1 (GDH 1) & At5g 18170 & 44.53 & -0.174 & 26.98 & 65.9 \\
\hline & Glutamate dehydrogenase 2 (GDH 2) & At5g07440 & 44.70 & -0.148 & 17.71 & 58.6 \\
\hline & Glutamate dehydrogenase 3 (GDH 3) & At3g03910 & 44.53 & -0.200 & 19.23 & 58.9 \\
\hline \multirow[t]{2}{*}{3} & Pyruvate dehydrogenase E1 (beta subunit) & At5g50850 & 39.18 & -0.002 & 24.79 & 47.1 \\
\hline & Pyruvate dehydrogenase E1 (beta subunit) & At1g59900 & 43.06 & -0.330 & 17.36 & 42.9 \\
\hline \multirow[t]{2}{*}{4} & ADP/ATP carrier protein 2 (ANT 2) & At5g13490 & 41.75 & -0.111 & 11.55 & 36.4 \\
\hline & VDAC 2 (Porin 2) & At5g15090 & 29.21 & -0.183 & 8.12 & 22.7 \\
\hline \multirow[t]{2}{*}{5} & Manganese superoxide dismutase (SOD) & At3g56350 & 26.89 & -0.198 & 9.16 & 32.4 \\
\hline & Manganese superoxide dismutase (SOD) & At1g08830 & 15.10 & -0.076 & 7.78 & 60.2 \\
\hline \multirow[t]{2}{*}{6} & Nucleoside diphosphate kinase IV (NDPK) & At4g23900 & 25.77 & -0.156 & 11.72 & 31.6 \\
\hline & Nucleoside diphosphate kinase III (NDPK) & At4g11010 & 25.74 & -0.133 & 11.72 & 31.6 \\
\hline 7 & Heat stress protein $10(\mathrm{HSP} 10)$ & At1g14980 & 10.81 & -0.358 & 6.14 & 86.6 \\
\hline
\end{tabular}

${ }^{1}$ Spot numbers correspond to the numbers given in Figure 3

${ }^{2}$ Proteins were identified by MS/MS analysis. Data evaluation was carried out using the ProteinPilot software package and the A. thaliana protein database (tair release 8) as described in the Materials and Methods section.

${ }^{3}$ Accession numbers in A. thaliana

${ }^{4}$ ProteinPilot score for reliability of identifications. The score value is calculated as -( $\log ($ confidence [\%])).

Thus, a 99\% confident protein identification corresponds to a Score of 2.00 (46)

${ }^{5}$ Sequence coverage by identified peptides in percent. 


\section{$\underline{\text { Figure legends }}$}

Figure 1: In-gel enzyme activity stainings of the respiratory protein complexes from Arum maculatum. Mitochondria were isolated from the developmental stages $\beta, \gamma$ and $\delta$. As a control, measurements were also carried out for isolated mitochondria from Arabidopsis thaliana (A.t.). Mitochondria were solubilized by $5 \mathrm{~g}$ digitonin per g protein, separated by $1 \mathrm{D}$ BN-PAGE and either visualized by Coomassie staining (CC) or by in-gel activity staining for NADH dehydrogenase (I), succinate dehydrogenase (II) and cytochrome c oxidase (IV). Identities of protein complexes are indicated on the left or right side of the gels: I - complex I; II - complex II; III $_{2}$ - dimeric complex III; IVa and IVb - large and small form of complex IV; V - ATP-synthase; I+III 2 - supercomplex containing complex I and $\mathrm{III}_{2}$; $\mathrm{III}_{2}+\mathrm{IV}$ supercomplex composed of complex $\mathrm{III}_{2}$ and complex IV; I+III $2+\mathrm{IV}$ - supercomplex composed of complex I, dimeric complex III and monomeric complex IV.

Figure 2: 2D BN/SDS-PAGE of respiratory protein complexes from Arum maculatum developmental stages $\beta, \gamma$ and $\delta$ and from Arabidopsis thaliana (A.t.). Mitochondria were solubilized by $5 \mathrm{~g}$ digitonin per $\mathrm{g}$ protein. Proteins were visualized by silver staining. The identity of the protein complexes is given above the gels (for designations see Figure 1). Molecular masses of the standard proteins are given to the left or right of the gels.

Figure 3: Identity of selected mitochondrial proteins of Arum maculatum. Proteins of mitochondria isolated from the $\delta$ stage were resolved by 2D BN/SDS PAGE and visualized by Coomassie blue staining. Proteins $1-7$ were identified by mass spectrometry (Table I).

Figure 4: Immunological identification of carbonic anhydrases in mitochondrial fractions of Arum maculatum ( $\delta$ stage) and Arabidopsis thaliana (A.t). Proteins were separated by 2D BN/SDS-PAGE and afterwards blotted onto nitrocellulose. The position of the $\mathrm{I}+\mathrm{III}_{2}$ supercomplex $\left(\mathrm{I}+\mathrm{III}_{2}\right)$ and complex I (I) is given above the blots.

Figure 5: Immunological detection of alternative oxidase. Mitochondrial fractions of Arum maculatum appendices (developmental stages $\beta, \gamma$ and $\delta$ ) and Arabidopsis thaliana (A.t.) were resolved by 1D SDS-PAGE and either Coomassie stained or blotted onto nitrocellulose and developed with antibodies directed against AOX. Molecular masses of standard proteins are given to the left of the gel.

Figure 6: Immunological detection of alternative oxidase after resolution of mitochondrial fractions of Arum maculatum appendices (developmental stages $\beta, \gamma$ and $\delta$ ) and Arabidopsis thaliana (A.t.) by 2D BN/SDS-PAGE. Molecular masses of the standard proteins are given above the gel (native gel dimension) or to the right (SDS dimension). 
Fig. 1

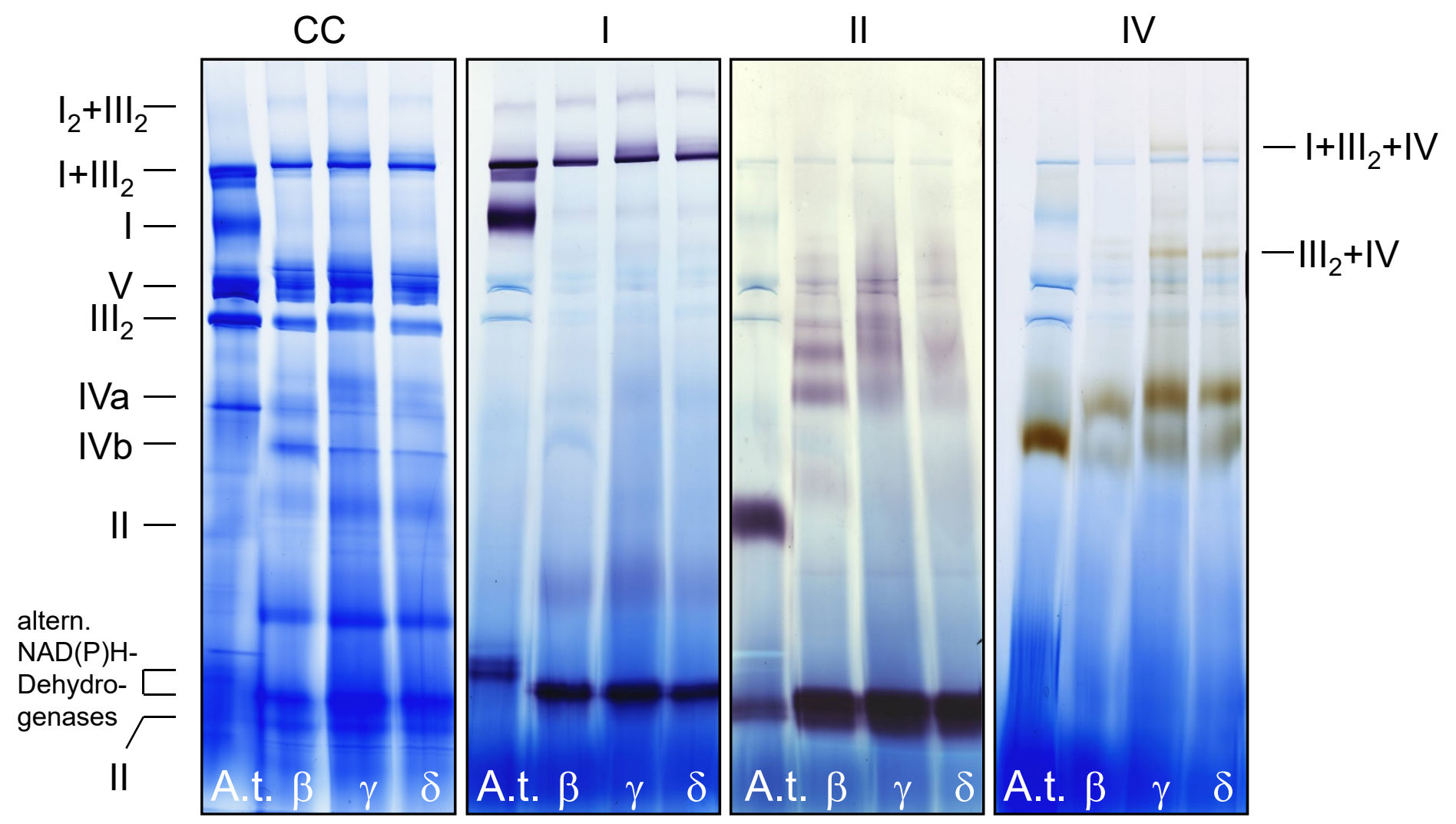


Fig. 2

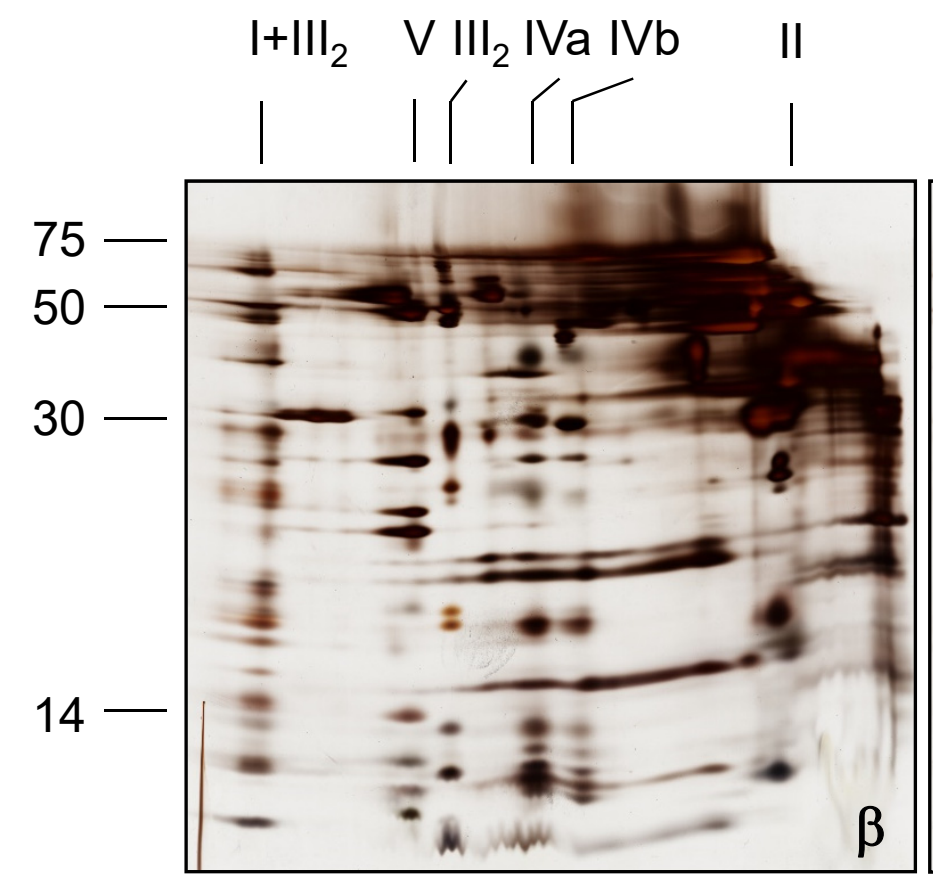

$\mathrm{I}+\mathrm{III}_{2} \quad \mathrm{~V} \mathrm{III} \mathrm{I}_{2} \mathrm{IVa} \mathrm{IVb} \quad \mathrm{II}$

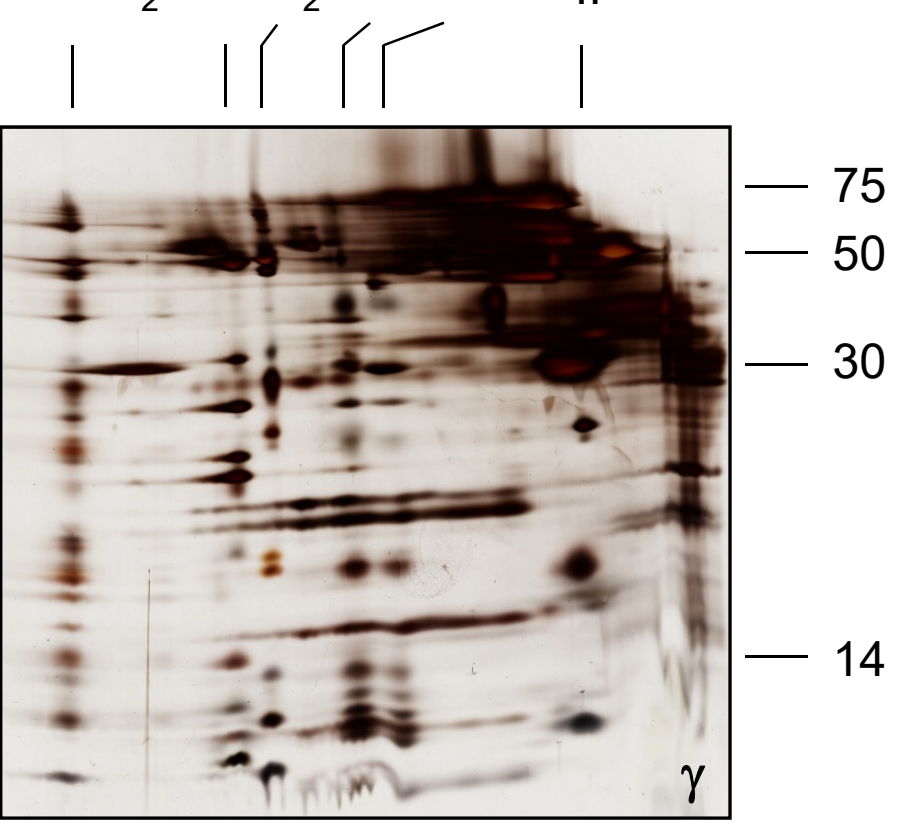

$\mathrm{I}+\mathrm{III} \mathrm{I}_{2} \mathrm{~V} \mathrm{III}_{2}$ IVa IVb

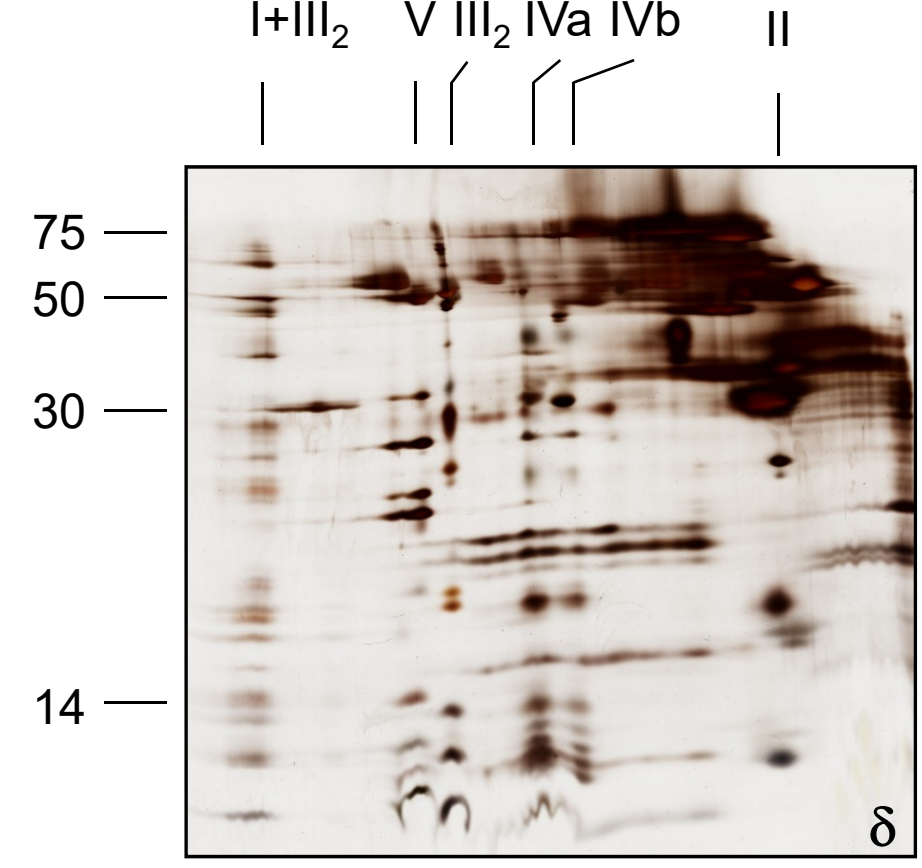

$I+I I_{2} \mid V\left\|_{2}^{F_{1}} I V\right\|$

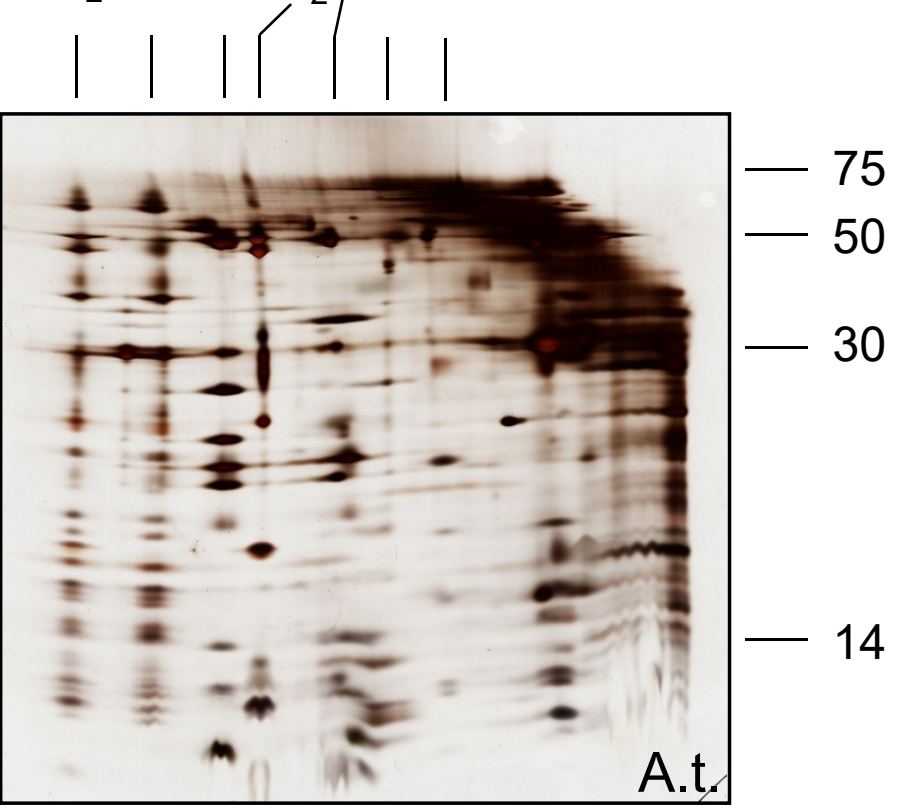


Fig. 3

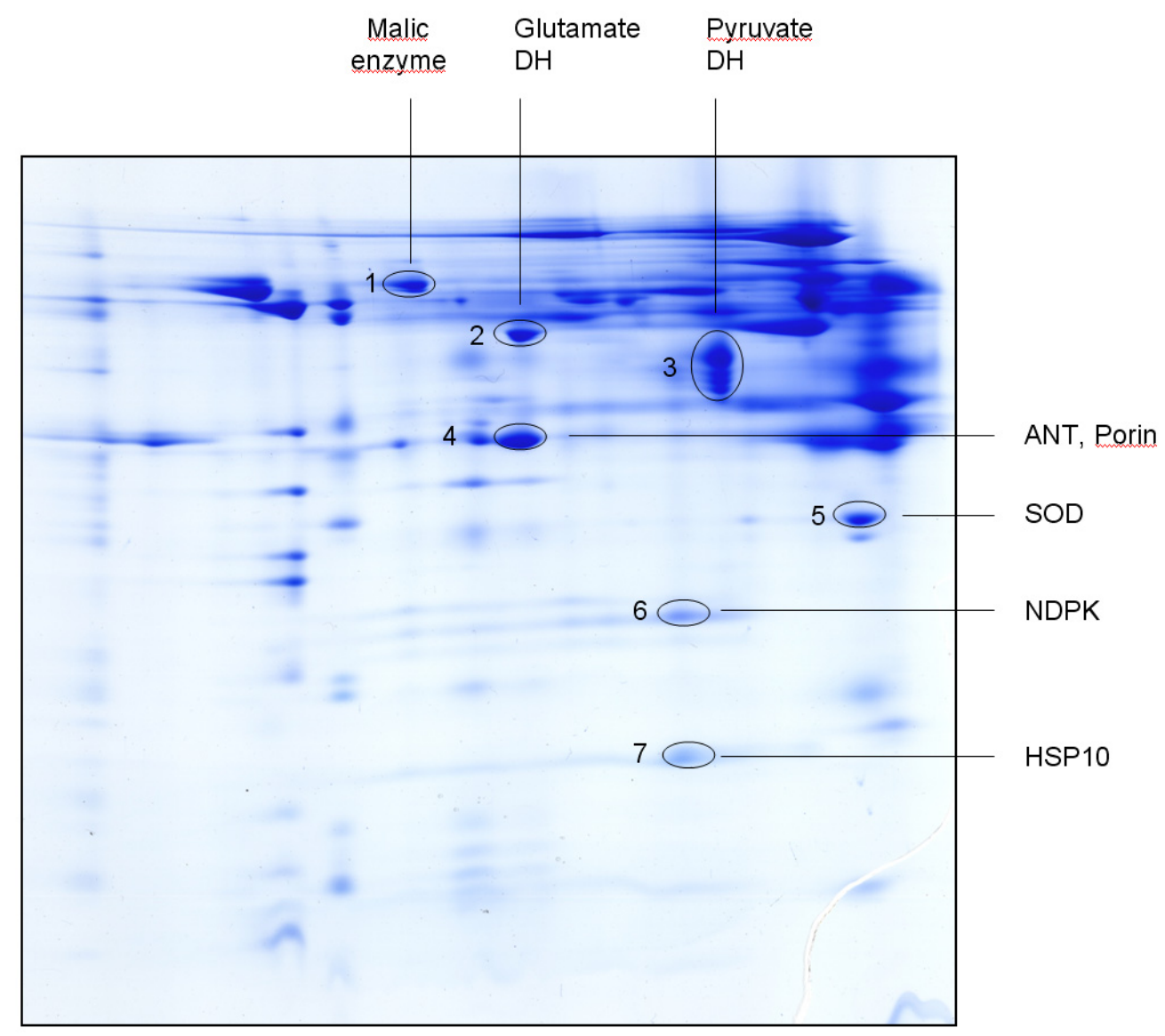


Fig. 4

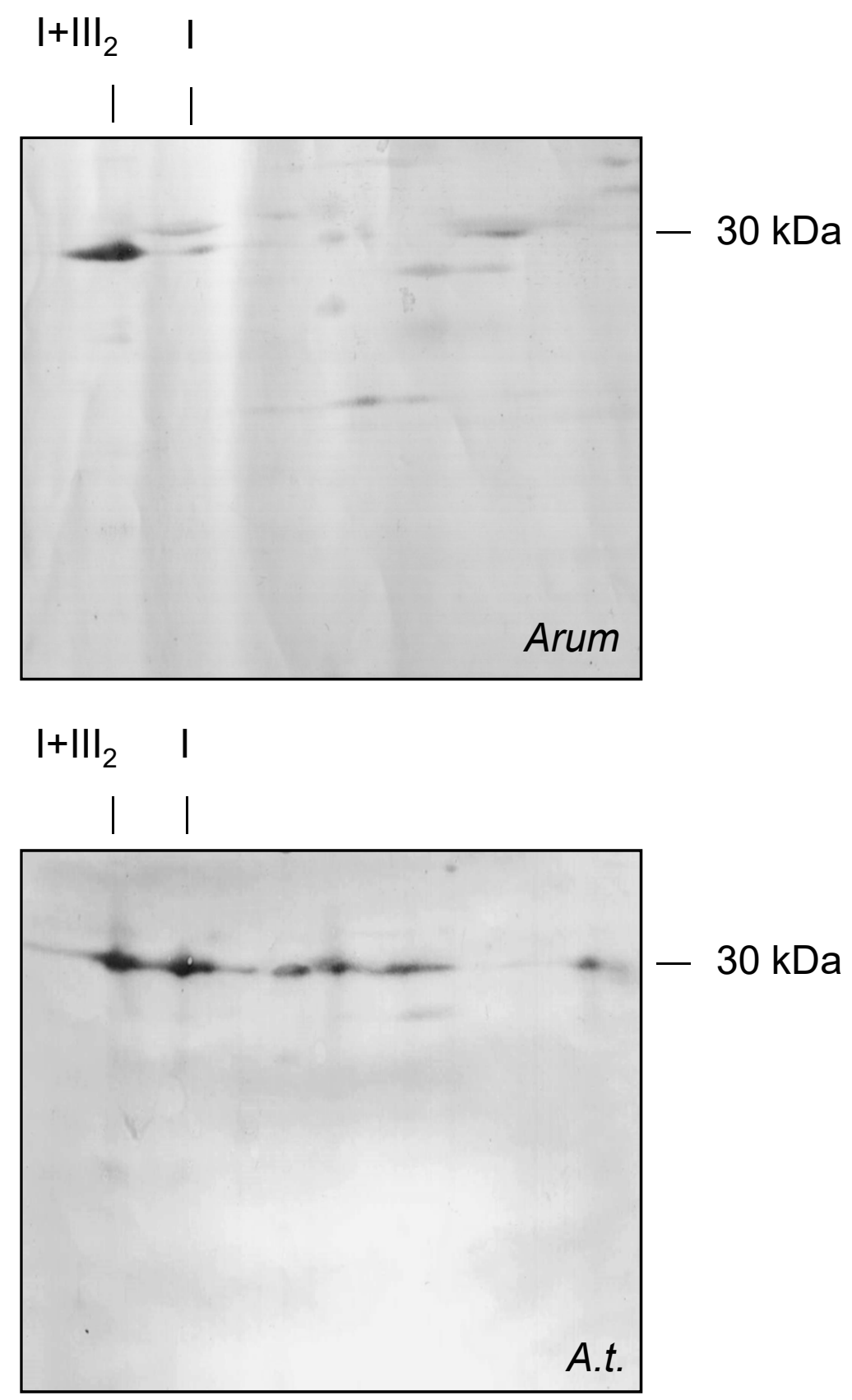


Fig. 5

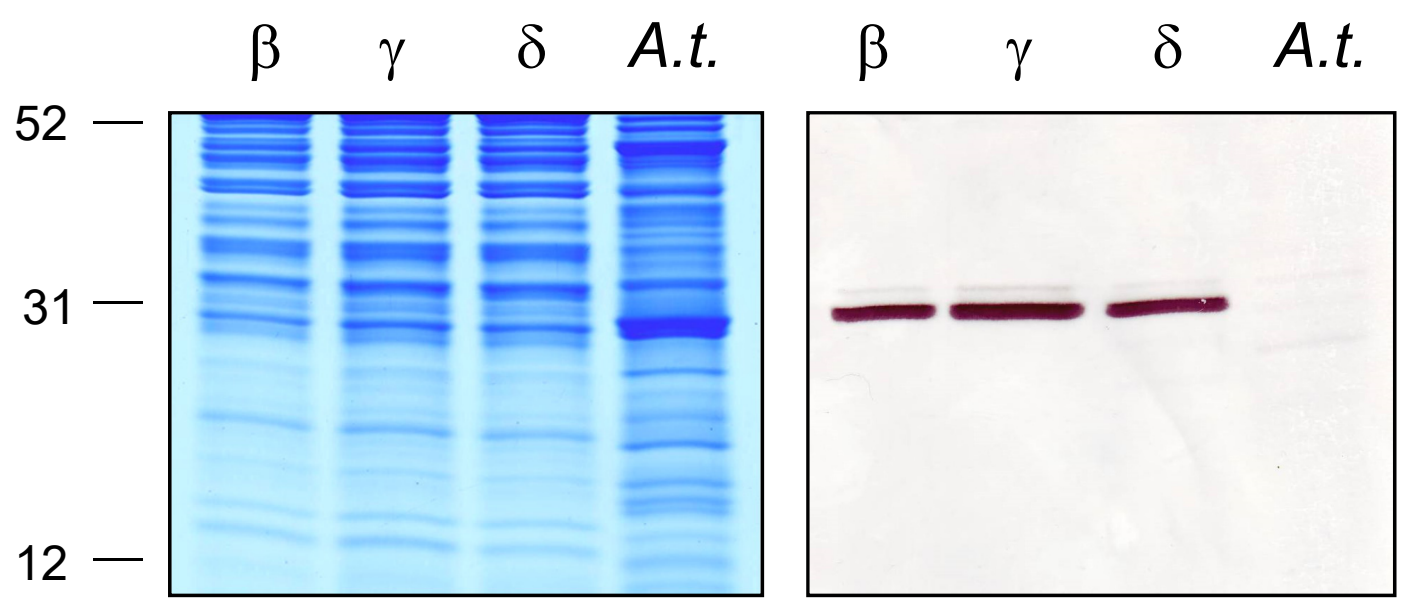


Fig. 6

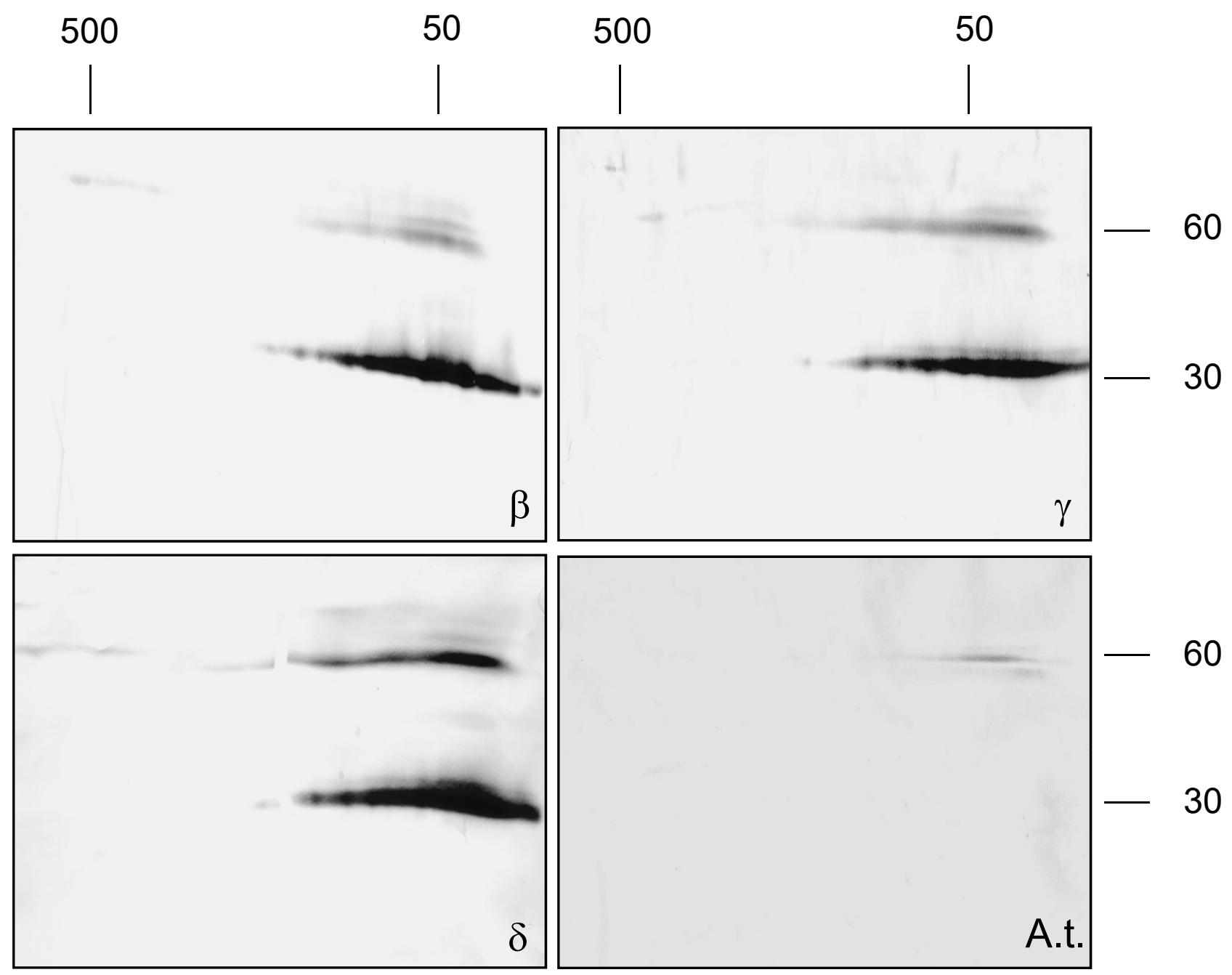

